\title{
Kinetic Modeling of Esterification Reaction of Free Fatty Acids Present in Macauba Oil Using a Cationic Resin as Catalyst
}

Daniel Bastos de Rezende ${ }^{1 *}$, Carlos Augusto Silva², Vânya Márcia Duarte Pasa² and Maria Helena Caño de Andrade $^{1}$

1. Department of Chemical Engineering, Federal University of Minas Gerais, Belo Horizonte 31270-901, Brazil

2. Department of Chemistry, Federal University of Minas Gerais, Belo Horizonte 31270-901, Brazil

\begin{abstract}
The cost of raw materials has the largest contribution to the final price of biodiesel produced by traditional routes, currently adopted in most industrial scale processes. That contribution comes from the need to use edible and noble oils, with low acidity, such as soybean oil. This work proposes the use of Macauba oil, a vegetable oil in focus in the State of Minas Gerais, Brazil, in which the current extractive yield generates a raw material with high acidity, therefore, not suitable to be used in biodiesel production. To make it technically feasible, a cationic exchange resin, the Purolite CT275DR, was used as a catalyst for esterification reaction with samples of Macauba oil, aiming to reduce its acidity. The resin can be reused, regenerated and easily removed from the reaction product, reducing costs with catalyst and purification stages. As a result of this work, in a sample of oil with an initial acidity of about $10 \% \mathrm{~m} / \mathrm{m}$ were achieved acidity reductions up to $97 \%$ by using cationic resins as catalyst, demonstrating its potential use in the oil pretreatment step. Additionally, the data collected during all the analysis made it possible to define the chemical kinetic of the esterification reaction.
\end{abstract}

Key words: Esterification, chemical kinetic, cationic resin, Acrocomiaaculeata, free fatty acids.

\section{Introduction}

Biodiesel is a renewable, biodegradable and eco-friendly fuel obtained from vegetable oil or animal fat or other source of triglycerides, and which can be used alone or blended with mineral Diesel. The most common route used to produce biodiesel in large scale is the transesterification reaction, in which the triglycerides react with short chain alcohol in the presence of a catalyst, generating glycerol and alkyl ester, the biodiesel [1].

Approximately $85 \%$ of biodiesel production cost is due to the price of vegetable oil used as the source of triglycerides [2]. There are several sources of triglycerides available. Raw materials with low cost are those with high acidity, such as frying oils, not

*Corresponding author: Daniel Bastos de Rezende, Ph.D./professor, research field: biofuels and process simulation. E-mail: bastos_rezende@hotmail.com. edible oils, and oils extracted from fruits picked from the ground instead of picked directly from the trees. However, such materials have restrictions to be used in the production of biodiesel by transesterification process via alkaline catalysis, the most traditional and consolidated industrial route. This kind of raw material needs a pre-treatment step to reduce the acid content, raising the production costs and consequently the product [3].

The Macauba (Acrocomiaaculeata) is an oleaginous palm in focus in the state of Minas Gerais, whose extractive harvest classify it as a raw material of high acidity, therefore not suitable for biodiesel production by conventional processes. Macauba oil production may reach $5,000 \mathrm{~kg} / \mathrm{ha}$, higher than the soybean oil production, just $375 \mathrm{~kg} / \mathrm{ha}[3,4]$.

The use of oils with high acidity in the biodiesel production via alkaline catalysis results in an 
undesirable parallel reaction called saponification, in which the free fatty acids react with the catalyst, producing soap. The production of soap causes decrease in production yield and problems related to phase separation. Therefore, in these cases, there must be a de-acidification step before the transesterifications reaction [5]. In the de-acidification step, the free fatty acids can be removed from oil either chemically (caustic neutralization) and physically (removal by steam).

It is the most critical step of oil refining and with the higher cost due to neutral oil losses. In chemical refining, there is an upper limit of oil acidity. High contents of free fatty acids can cause neutral oils losses and effluent generation due to soap formation and emulsification. In physical refining there is no limitation regarding the free fatty acid content. However, this treatment demands too much energy. In addition, undesirable changes may occur in the oil due to the high temperatures used in the process [6].

Another possibility is the esterification reaction, in which the free fatty acid molecules react with short chain alcohol molecules in the presence of an acid catalyst to produce alkyl ester and water. This process has been applied in some plants, using homogeneous acid catalysts. However, homogeneous catalysts have disadvantages such as the need for a post-treatment process to remove the catalyst, the effluent generation and the impossibility to recover and reuse the catalyst [7].

In this work, a commercially available cation exchange resin, Purolite CT275DR, is used as heterogeneous catalyst for the esterification reaction of Macauba oil samples with high acidity. The use of cationic resin as heterogeneous catalyst has the advantage of easily removal after esterification and its possibility to be reused in the same process. The aim of this study was to perform esterification experiments to determine the kinetic model of this reaction.

\section{Experiments}

To determine the kinetics model and the rate constant of the esterification reaction, samples of Macaubapulp oil internally produced were used, extracted from fruits collected on the campus of the Federal University of Minas Gerais, Brazil, and in a rural area of the state of Minas Gerais, Brazil. The alcohol used in the reaction was $99.5 \%$ anhydrous ethanol. Ethanol was chosen as the short chain alcohol due to its renewable source origin and for being widely produced from sugar cane in Brazil.

\subsection{Esterification and Kinetic Modeling}

Five batches of the esterification reaction with the cationic resin as the catalyst were conducted for eight hours each, to determine the kinetic law and the rate constant. All five batches were carried out using the same resin without any washing or regeneration processes to verify the maintenance of its catalytic activity. To determine the kinetic model a sample was collected every hour to measure the conversion of free fatty acids into alkyl esters. This evaluation was performed by determination of the acid number by acid-base titration, and the concentration of ethanol was determined indirectly through the evaporation loss. The Macauba oil used has initial acidity of about $10 \%$ by weight of oleic acid.

The cation exchange resin Purolite CT275DR, donated by Purolite representative in Brazil, Kurita LTDA, was used as the esterification catalyst. It is a strong acid cation exchange resin with the polymer matrix of styrene and divinylbenzene and sulfonic acid groups, whose main characteristics are listed in Table 1 and the chemical structure are shown in Fig. 1.

To determine the kinetic model, the reactions were carried out at the boiling point of the mixture (bath temperature of $85^{\circ} \mathrm{C}$ ), with weight ratio of ethanol/oil of $1: 1,20 \%$ of resin, related to the components weight (ethanol and oil), during $8 \mathrm{~h}$ with sampling every $1 \mathrm{~h}$. These reaction parameters were chosen according to the positive results achieved in Master's degree work completed in 2011 [8].

Due to the partial miscibility of the components, the 
Table 1 Physical and chemical properties of Purolite CT275DR.

\begin{tabular}{lll}
\hline Properties & Unit & Value \\
\hline Humidity & $\%$ & $\leq 3$ \\
Original ionic form (non-fixed ion) & - & $\mathrm{H}^{+}$ \\
Ionic exchange capacity & $\mathrm{eq} \cdot \mathrm{kg}^{-1}$ (dry) & $\geq 5.20$ \\
Mean size & $\mathrm{Mm}$ & 0.65 to 0.90 \\
Specific mass & $\mathrm{g} \cdot \mathrm{mL}^{-1}$ & 1.20 \\
Pore volume & $\mathrm{mL} \cdot \mathrm{g}^{-1}$ & 0.4 to 0.6 \\
Specific superficial area & $\mathrm{m}^{2} \cdot \mathrm{g}^{-1}$ & 20 to 40 \\
Pore mean diameter & $\AA$ & 400 to 700 \\
Operation temperature & $\AA$ & $\leq 145$ \\
\hline
\end{tabular}

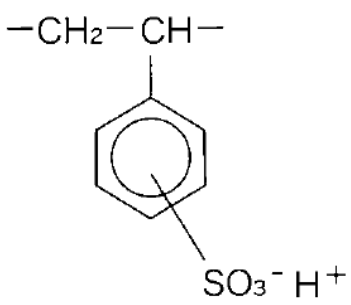

Fig. 1 Chemical estructureof Purolite CT275DR.

process requires a high degree of mixing. However, due to the sensitivity of the resin to mechanical shock, mechanical stirring or by means of magnetic stirring or impellers must be avoid. In this work, the reaction was performed in a rotary evaporator equipment (FISATOM), the condenser and the condensate collector flask were replaced by a Liebig condenser with circulating water. A rotation of $100 \mathrm{rpm}$ was used. This reaction system, from now on called rotatory reactor which is shown schematically in Fig. 2.

The yield of the esterification was monitored by determining the evaporative loss and the acidity, according to the procedure described previously. The triglycerides content was determined using the method of differences.

As the molar amount of ethanol is excessively high, about 60:1 with respect to the free fatty acids, the ethanol concentration may be considered constant during the reaction. The stoichiometry relation of the esterification reaction is $1: 1$. Therefore, the kinetic model depends only on the concentration of free fatty acids.

The determination of the kinetic model of esterification catalyzed by cationic resin was conducted following the integral method. In this method, a trial and error procedure is used to check the order of the reaction. After the assumption of an order, the differential equation used to model the batch system is integrated. If the assumed order is the real order, the corresponding graph of the integrated equation must be linear [9]. Considering the excess of ethanol, its concentration can be considered constant during the reaction. Hence, the reaction rate will not be influenced by the ethanol concentration. In this case, in a batch reactor at a constant volume, the following molar balance can be used:

$$
\frac{d[A]}{d t}=r
$$

where, $[A]$ is the concentration of free fatty acids. The free fatty acid consumption rate, $r$, obeys the following kinetic model:

$$
r=k[A]^{\alpha}
$$

where, $k$ is the rate constant, which the unit will depend on the reaction order, and $\alpha$ is the reaction order.

\subsection{Determination of the Fatty Acid Composition}

To determine the fatty acid composition of the degummed Macauba oil, gas chromatography detection was performed according to the following procedure. The analyses were conducted using a gas chromatographer with a flame ionization detector (GC-FID). For injection of the samples, hydrolysis was performed, followed by methylation of the oils. For this purpose, approximately $10 \mathrm{mg}$ of oil was 


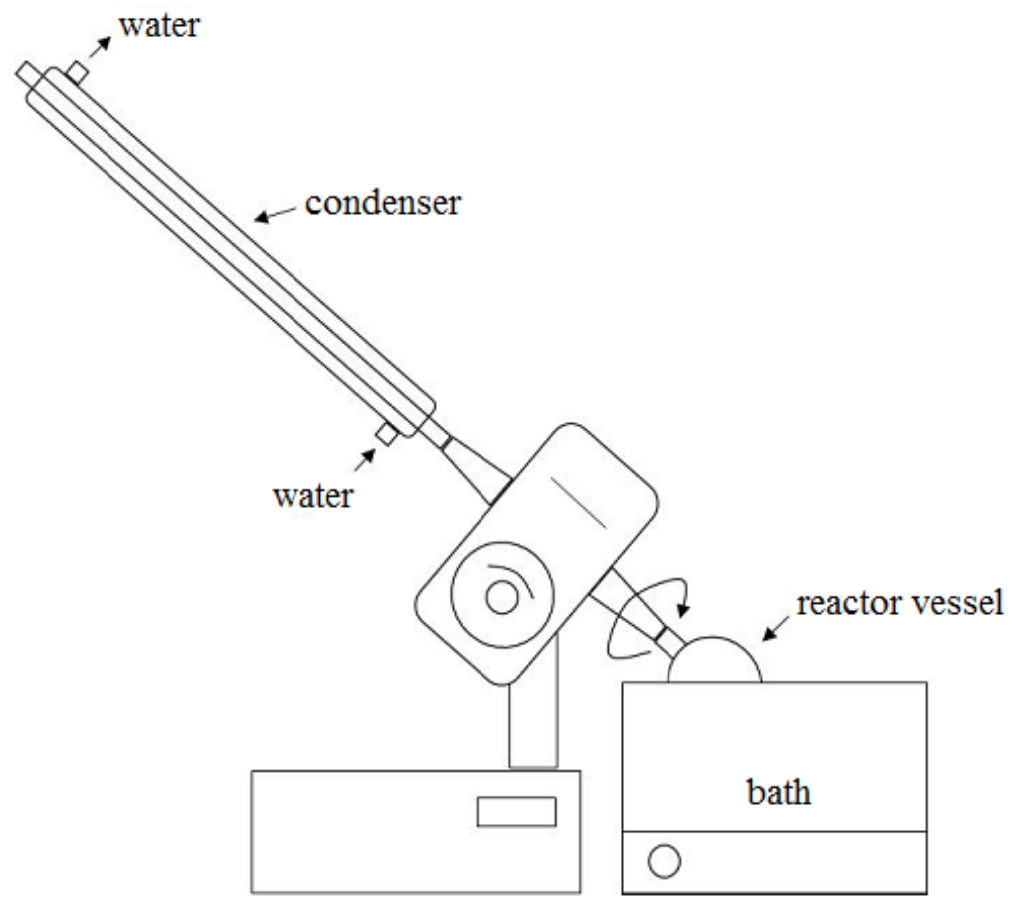

Fig. 2 Schematic drawing of the rotatory reactor.

dissolved in $100 \mu \mathrm{L}$ of $95 \%$ ethanol $/ 5 \% 1 \mathrm{~mol} / \mathrm{L}$ potassium hydroxide solution in a vial. The sample was stirred for $10 \mathrm{~s}$. Next, it was heated for $20 \mathrm{~min}$ at $70{ }^{\circ} \mathrm{C}$ in a thermostatic bath [10]. After cooling, 400 $\mu \mathrm{L}$ of $20 \%$ hydrochloric acid and $600 \mu \mathrm{L}$ of ethyl acetate were added. After resting for $5 \mathrm{~min}$, a $300 \mu \mathrm{L}$ aliquot of the organic phase was removed, placed in a vial and dried by evaporation, thus obtaining the free fatty acids. The free fatty acids were methylated with $100 \mu \mathrm{L}$ of $\mathrm{BF}_{3} / 14 \%$ methanol and heated for $10 \mathrm{~min}$ in a water bath at $70{ }^{\circ} \mathrm{C}$. Next, they were diluted with $500 \mu \mathrm{L}$ of methanol and analyzed in the GC-2010 Shimadzu GC-FID. A $60 \mathrm{~m} \times 0.25 \mathrm{~mm}$ SP2340 column with a film thickness of $0.20 \mu \mathrm{m}$ was used. The selected temperature gradient was maintaining $140{ }^{\circ} \mathrm{C}$ for $5 \mathrm{~min}$, heating at $4{ }^{\circ} \mathrm{C} / \mathrm{min}$ to $240{ }^{\circ} \mathrm{C}$, and remains at this temperature for $9 \mathrm{~min}$. The temperatures of the injector and detector were $250{ }^{\circ} \mathrm{C}$ and $260{ }^{\circ} \mathrm{C}$, respectively. Helium was used as the carrier gas, with a linear velocity of $28 \mathrm{~cm} / \mathrm{s}$. The volume of injection was $1 \mu \mathrm{L}$, and the split was $1 / 50$.
The identification of the peaks was performed by comparison with the SUPELCO37 methylated fatty acid standards.

\subsection{Determination of the Free Fatty Acids Content}

The acidity is measured through acid-base titration, according to methodology AOCS Cd3d-63.10. For the acid-base titration, it was used $25 \mathrm{~mL}$ of a solvent consisting of ethanol $99.5 \%$ and ethyl ether $99.5 \%$ in volume ratio of 2:1. $\mathrm{KOH}$ (potassium hydroxide) 0.1 $\mathrm{mol} / \mathrm{L}$ was used as the titrant, and phenolphthalein solution $1 \%$ as the indicator. The calculation of acidity is done as the following:

$$
\% \text { oleicacid }=\frac{V \times[\mathrm{KOH}] \times 28.2}{M}
$$

where,

$V=$ volume of titrant used, $\mathrm{mL}$;

$[\mathrm{KOH}]=$ titrant concentration, $0.1 \mathrm{~mol} / \mathrm{L}$;

28.2 = constant based on the oleic molar weight and units conversions;

$M=$ sample mass, $\mathrm{g}$. 


\subsection{Determination of the Ethanol Content}

The determination of the ethanol content was carried out indirectly by determining the evaporative loss, gravimetric method traditionally used by Fiat Chrysler Automobiles in Brazil, to determine the ethanol content in oil samples. The samples were placed in Petri dishes in the amount of 1 to $2 \mathrm{~g}$ and weighed on an analytical balance. After that, the samples were maintained in an oven with air circulation at $80{ }^{\circ} \mathrm{C}$ for $60 \mathrm{~min}$. After evaporation, the solvent amount is estimated by mass loss of the samples.

\section{Results and Discussion}

The fatty acid composition of Macauba pulp oil is presented in Table 2.

The concentration of free fatty acids during the esterification was monitored by determining the acidity and the concentration of ethanol. Macauba oil samples used in the five batches had initial acidity close to $10 \%$ by weight of oleic acid. Figs 3 and 4 show the free fatty acids consumption and the percent reduction of free fatty acids during eight hours of reaction, respectively, in five batches, with each batch sequentially conducted using the same resin.

The results indicate that there is no significant reduction of catalytic activity of the resin, which keeps efficient for all batches. As Macauba oil samples showed slightly different initial acidity, Fig. 4 is composed of a normalization of these values, dealing with acidity reduction instead of the free fatty acids contents. In the Fig. 4, it is evident the maintenance of the catalytic activity of the resin. The differences in yield are due to the natural variability of the experimental procedure.

It is observed that in the first hour there is a rapid drop in acidity. After that, the acidity starts to decrease more slowly. As expected, this initial rapid consumption of free fatty acids may be associated with the initial availability of active sites on the resin and the largest driving force for the reaction due to the higher concentration of free fatty acids. By means of the integral method of analysis of the reaction order, it was found that the five batches presented a pseudo-first order behavior, as showed in Figs. (5-9).

Considering a pseudo-first order reaction, the rate constant, $k$, is given by the slope of $\ln \left(C_{A 0} / C_{A}\right)$ vs. time. Hence, through the experimental data and the linear regressions, the average rate constantis 0.3245 $\mathrm{h}^{-1}$. The kinetic model can be expressed as the following:

$$
-r_{A}=\left[0.3245\left(\frac{1}{h}\right)\right] C_{A}
$$

where, $r_{A}$ is expressed in $\mathrm{mol} \cdot \mathrm{g}^{-1} \cdot \mathrm{h}^{-1}$ and $C_{A}$ in $\mathrm{mol} \cdot \mathrm{g}^{-1}$.

With the kinetic model in hands, it is possible to obtain important results related to reactor projects and process simulation and process optimization. For instance, it is possible to calculate the residence time necessary to achieve certain conversion of the free fatty acids content into alkyl esters and to determine the reactor volume necessary to achieve this conversion.

Table 2 Fatty acid composition of Macauba pulp oil.

\begin{tabular}{lll}
\hline Common name & Notation $^{\mathrm{a}}$ & Composition mass (\%) \\
\hline Tetradecanoicacid & $\mathrm{C} 14: 0$ & $0.04 \%$ \\
Palmiticacid & $\mathrm{C} 16: 0$ & $16.17 \%$ \\
Palmitoleicacid & $\mathrm{C} 16: 1$ & $1.91 \%$ \\
Margaricacid & $\mathrm{C} 17: 0$ & $0.05 \%$ \\
Stearicacid & $\mathrm{C} 18: 0$ & $2.79 \%$ \\
Oleicacid & $\mathrm{C} 18: 1$ & $66.52 \%$ \\
Linoleicacid & $\mathrm{C} 18: 2$ & $10.59 \%$ \\
Arachidicacid & $\mathrm{C} 20: 0$ & $0.13 \%$ \\
Linolenicacid & $\mathrm{C} 18: 3$ & $0.85 \%$ \\
Others & & $0.94 \%$ \\
\hline
\end{tabular}

${ }^{a}$ Notation of fatty acids, C:D, where C is the number of carbon atoms and $\mathrm{D}$ is the number of double bonds in the fatty acid. 


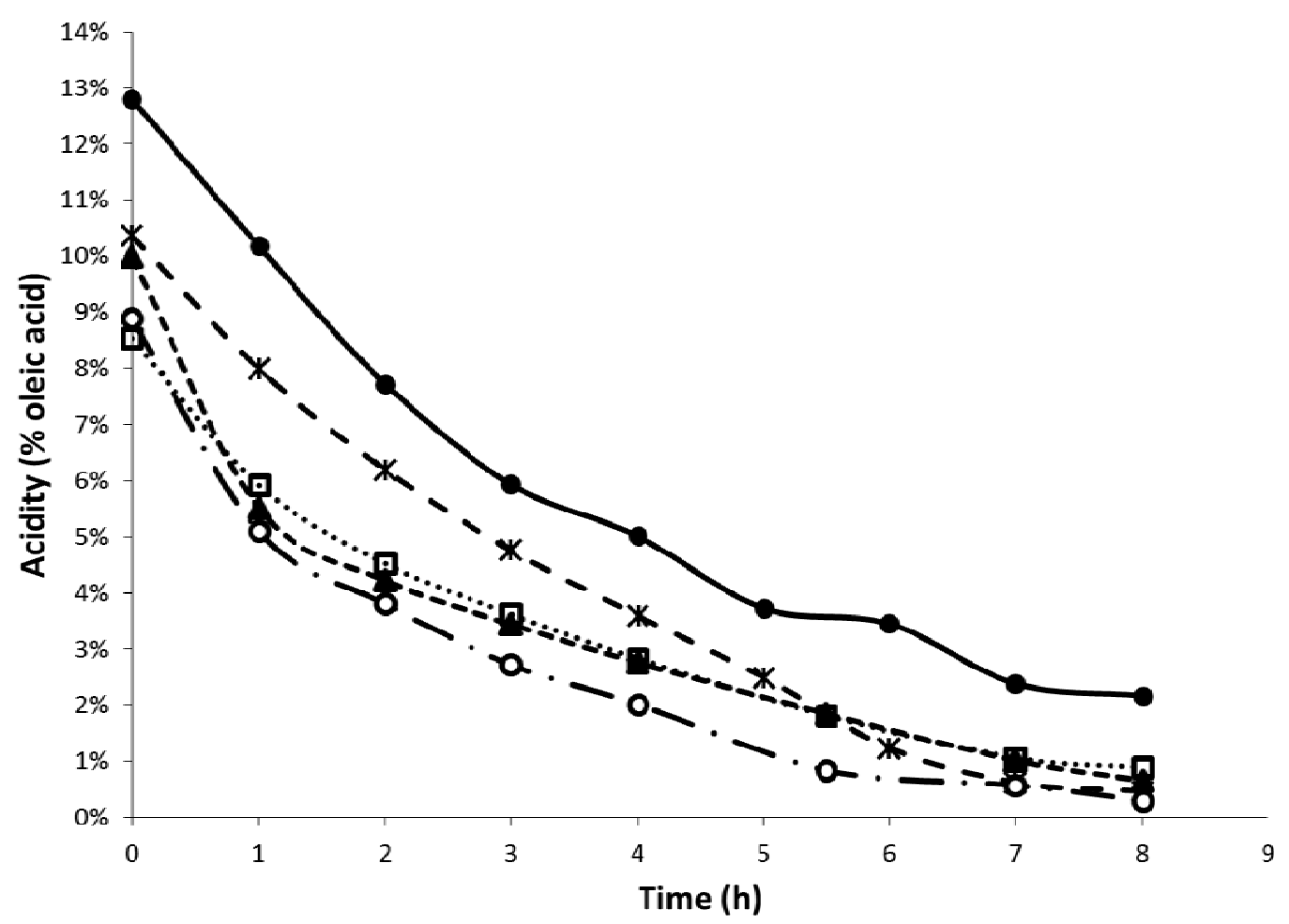

Fig. 3 Acidity value of the Macauba oil sample during the esterification reaction.

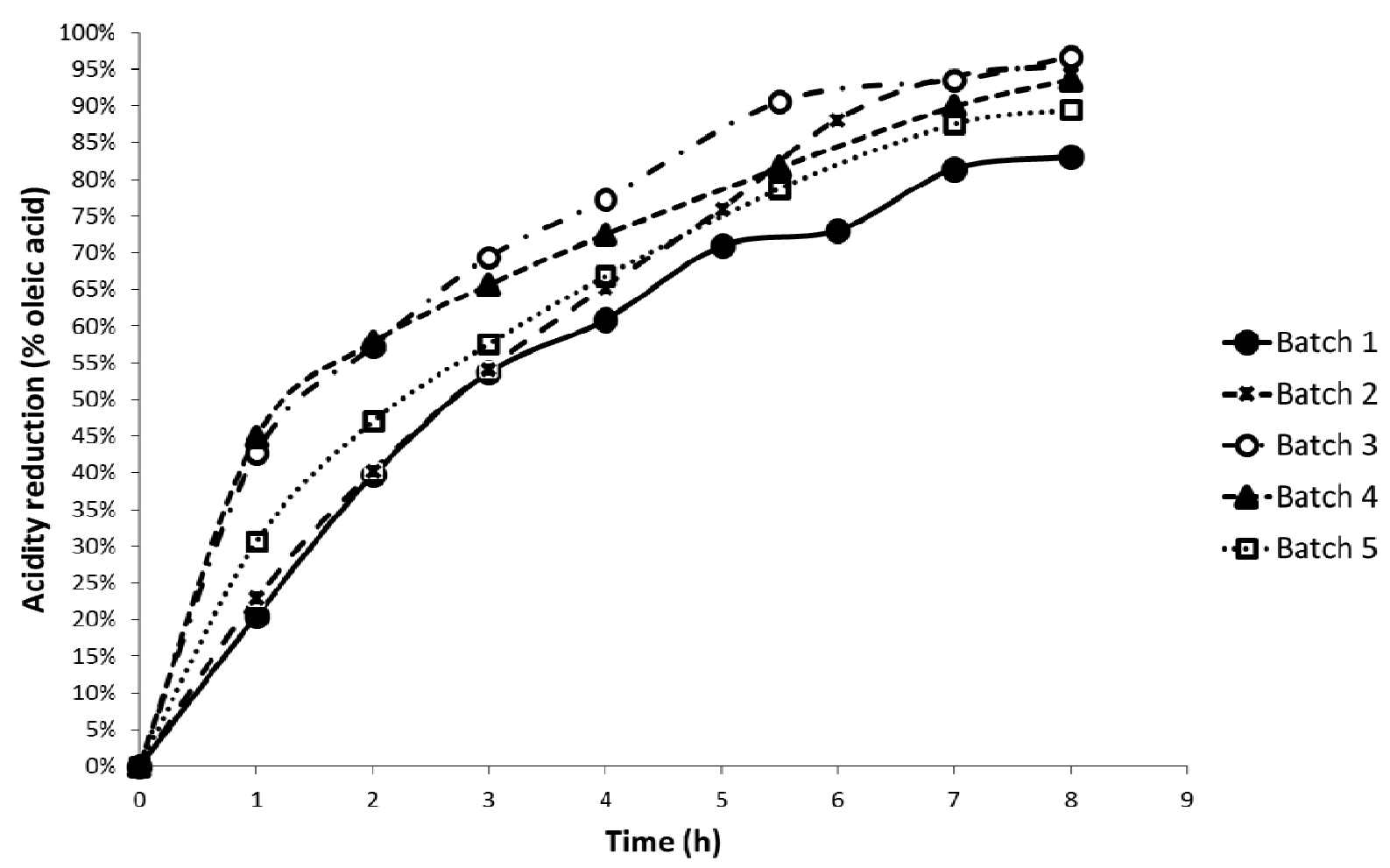

Fig. 4 Acidity reduction of the Macauba oil sample during the esterification reaction. 

Macauba Oil Using a Cationic Resin as Catalyst

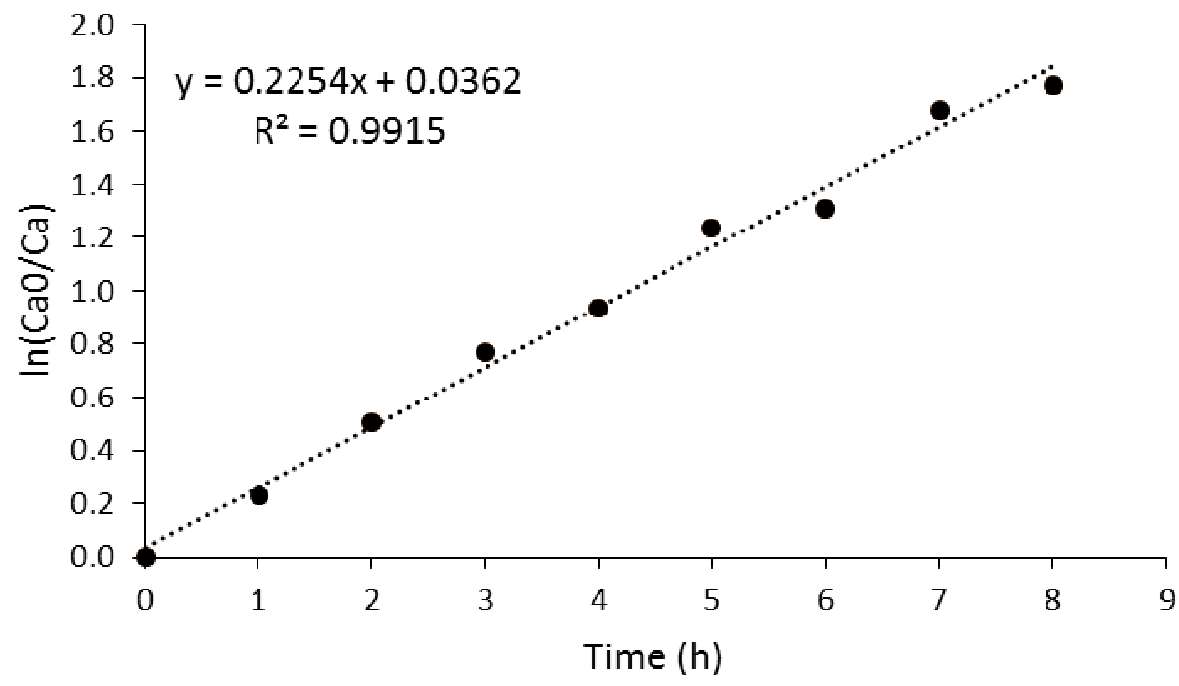

Fig. 5 Linear regression considering a pseudo first order behavior in the firstbatch.

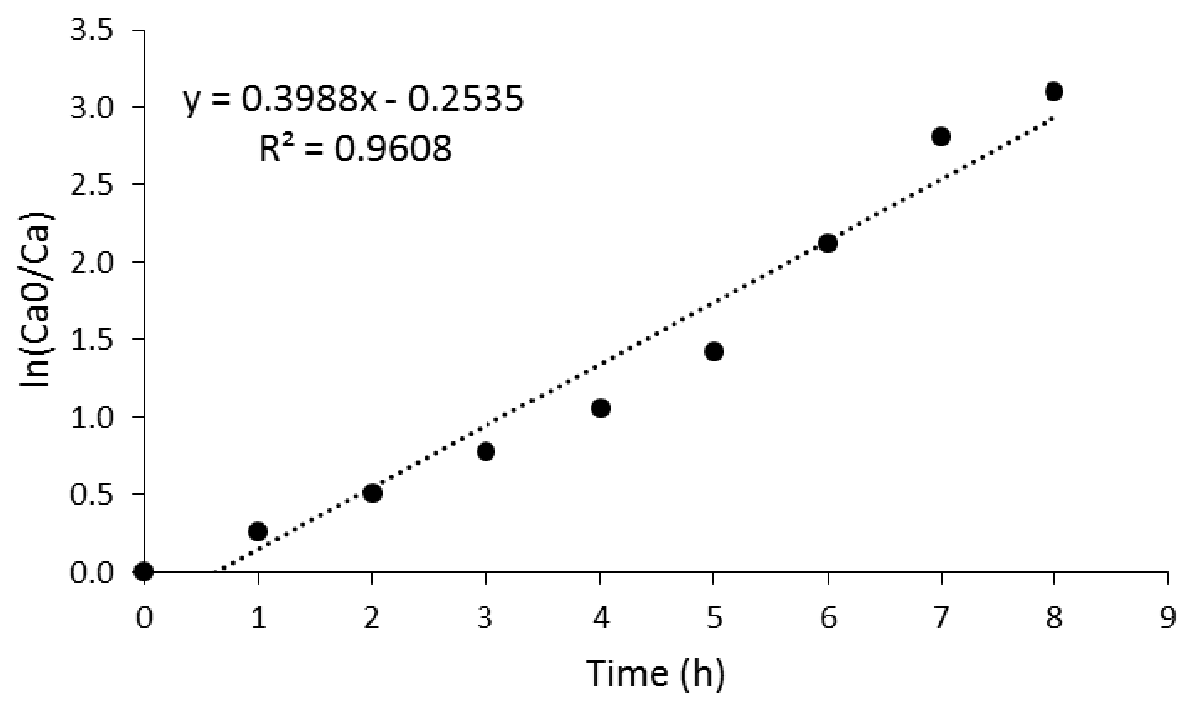

Fig. 6 Linear regression considering a pseudo first order behavior in the second batch.

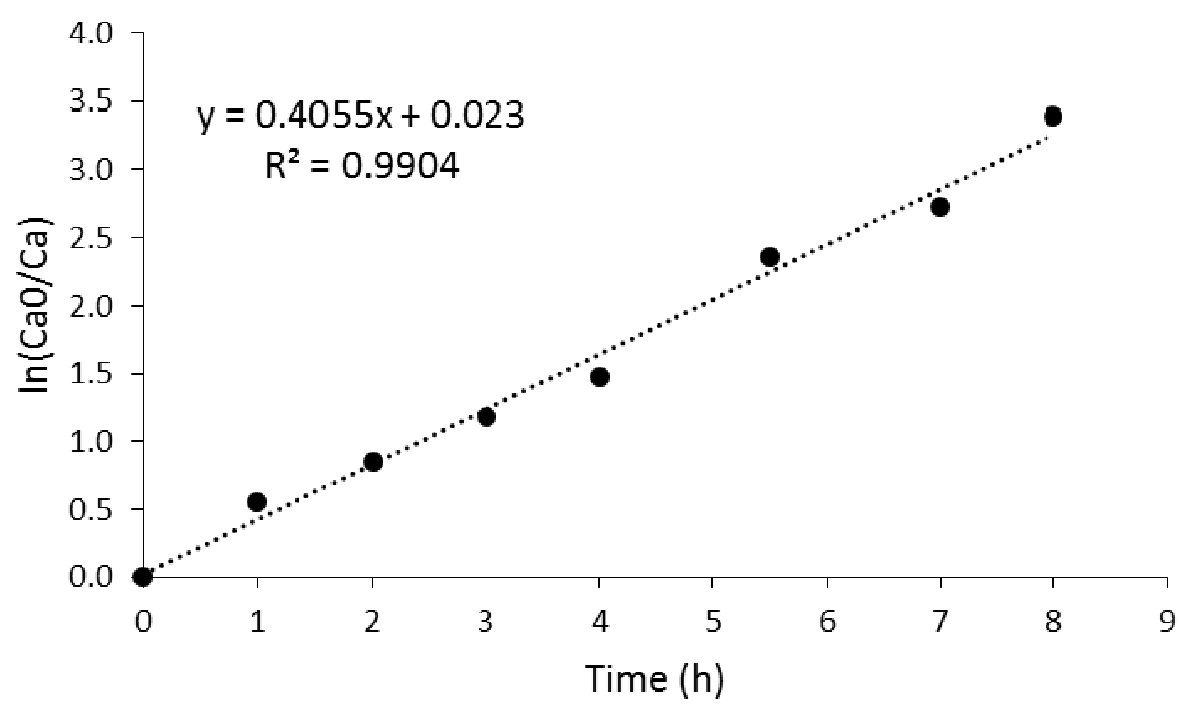

Fig. 7 Linear regression considering a pseudo first order behavior in the third batch. 


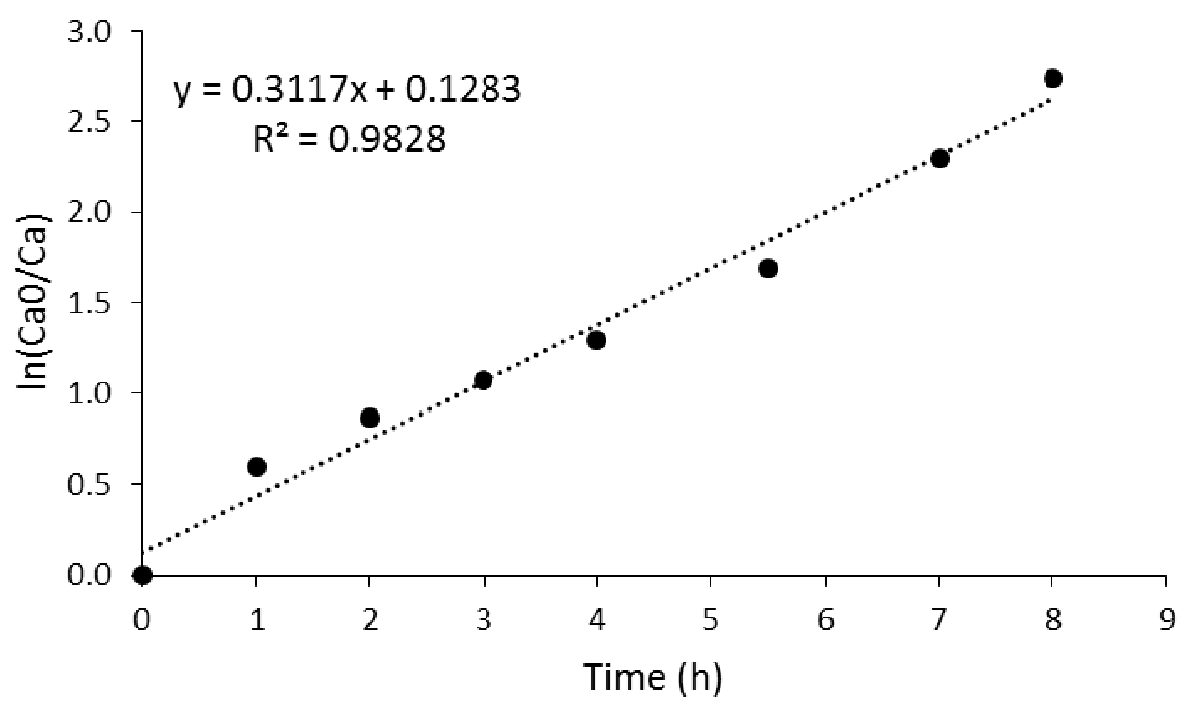

Fig. 8 Linear regression considering a pseudo first order behavior in the fourth batch.

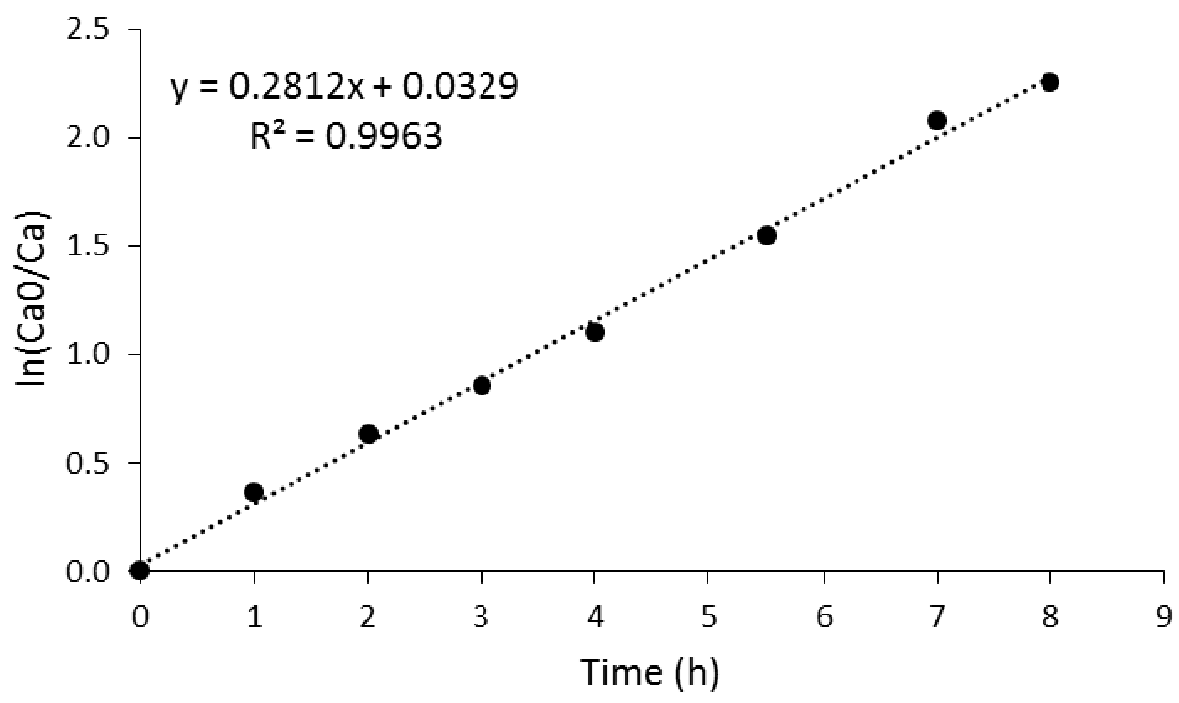

Fig. 9 Linear regression considering a pseudo first order behavior in the fifth batch.

\section{Conclusions}

The cation exchange resin is an alternative with great potential as catalyst of the esterification of free fatty acids and can be used as a pretreatmentstep of raw materials with high acidity in order to produce biodiesel. The use of the resin is advantageous because of its recoverability and reusability.

Under the experimental conditions studied, samples with initial acidity of $10 \%$, the kinetic model showed first order behavior in the concentration of free fatty acids, considering the constant concentration of ethanol. The constant average rate was $0.3245 \mathrm{~h}^{-1}$.

\section{References}

[1] Knothe, G., Van Gerpen, J., and Krall, J. 2005. The Biodiesel Handbook. Illinois: AOCS Press.

[2] Kouzu, M., Nakagaito, A., and Hidaka, J. 2011. "Pre-esterfification of FFA in Plant Oil Transesterifiedinto Biodiesel with the Help of Solid Acid Catalyst of Sulfonatedcation-Exchange Resin.” Applied Catalysis A 405: 36-44.

[3] Costa, M. A., Silva, P. S. C., and Valle, P. W. P. 2009. A Bioenergy: State of Minas Gerais Production-Chain and Co-Products. Pro-citta/sectes: Belo Horizonte.

[4] Santori, G., Di Nicola, G., Moglie, M., and Polonara, F. 2012. "A Review Analyzing the Industrial Biodiesel Production Starting from Vegetable Oil Refining.” Applied Energy 92: 109-32. 

Macauba Oil Using a Cationic Resin as Catalyst

[5] Lotero, E., Liu, Y., Lopez, D. E., Suwannakarn, K., Bruce, D. A., and Goodwin, J. G. 2005. "Synthesis of Biodiesel via Acid Catalysis.” Industrial \& Engineering Chemistry Research 44: 5353-63.

[6] Reiport, E. C. D., Rodrigues, C. E. C., and Meirelles, A. J. A. 2011. "Phase Equilibria Study of Systems Composed of Refined Babassu Oil, Lauric Acid, Ethanol, and Water at 303.2 K.” Chemical. Thermodynamics 43: 1784-90.

[7] Jacobson, K., Gopinath, R., Meher, L. C., and Dalai, A. K. 2008. "Solid Acid Catalyzed Biodiesel Production from Waste Cooking Oil.” Applied Catalysis B: Environmental
85: 86-91.

[8] Rezende, D. B. 2011. "Esterification and Transesterification of Macauba Oil with High Acidity Catalized by Ion Exchange Resins." Master's thesis, Federal University of Minas Gerais.

[9] Fogler, S. H. 2002 "Elements of Chemical Reaction Engineering.” 3rd Ed. Rio de Janeiro: LTC.

[10] Guo, H., Hu, C., and Qian, J. 2011. "Determination of Underivatized Long Chain Fatty Acids Using HPLC with an Evaporative Light-Scattering Detector.” Journal of the American Oil Chemists Society 89: 183-18. 